\title{
The association between psoriasis and health-related quality of life, work productivity, and healthcare resource use in Brazil ${ }^{*}$
}

\author{
Marco DiBonaventura ${ }^{1}$ \\ Cacilda da Silva Souza ${ }^{4}$ \\ Cristina Nunes Ferreira ${ }^{5}$
}

\author{
André Vicente Esteves de Carvalho ${ }^{2,3}$ \\ Haline Bianca Squiassi ${ }^{5}$
}

DOI: http:/ / dx.doi.org/10.1590/abd1806-4841.20186069

\begin{abstract}
BACKGROUND: Psoriasis is a chronic, immune mediated inflammatory condition that affects a significant amount of the global population. Yet geographic variability in the consequences of psoriasis warrants region-level analyses.

ОвлестіVE: The current study contributes to the psoriasis outcomes literature by offering a comprehensive assessment of the humanistic and economic burden in Brazil.

Methods: The 2012 Brazil National Health and Wellness Survey $(\mathrm{N}=12,000)$ was used to assess health-related quality of life (Short Form-12, version 2), work productivity, and healthcare resource use associated with experiencing psoriasis vs. no psoriasis, along with varying levels of psoriasis severity.

RESULTS: A total of 210 respondents reported diagnosis of psoriasis ( $\mathrm{N}=157,42$, and 11 reporting mild, moderate, and severe psoriasis, respectively). Compared with controls, respondents with psoriasis reported diminished mental component summary scores and health utilities, as well as increased presenteeism, activity impairment, and physician visits over the past six months, adjusting for covariates. Among those with psoriasis, physical health decreased as psoriasis severity increased. Although work productivity and healthcare resource utilization did not differ with psoriasis severity, the high rates of productivity loss (e.g. 45.5\% presenteeism in the severe psoriasis group) suggest an economic burden.

STUDY LIMITATIONS: Cost analyses were not performed, and cross-sectional patient-reported data limit causal conclusions and may reflect reporting biases.

CONCLUSIONS: Nevertheless, these results suggest a significant burden to patients with psoriasis across both humanistic and economic outcomes. The association between psoriasis and mental health aspects and health utilities were particularly strong and exceeded what would be considered clinically meaningful.
\end{abstract}

Keywords: Brazil; Health impact assessment; Health resources; Psoriasis; Quality of life

\section{INTRODUCTION}

Psoriasis is a chronic, immune-mediated inflammatory condition characterized by inflamed, scaly lesions that can affect any area of the skin. ${ }^{1}$ Prevalence studies conducted around the world show that psoriasis generally occurs in less than $5 \%$ of the population..$^{2-7}$ Yet, other reviews report substantial geographic variation, with a higher prevalence occurring in countries farther away from the equator. ${ }^{2,8}$ For example, one review reported a prevalence of $0.91 \%$ in the US compared with $8.5 \%$ in Norway. ${ }^{2}$

Psoriasis is a systemic disease, but seldom a life-threatening one. To date, there is no treatment cure and therapeutic strategies aim solely to reduce symptoms and maintain/improve health-related quality of life (HRQoL). Indeed, psoriasis can have a signif-

\footnotetext{
Received on 20.05.2016.

Approved by the Advisory Board and accepted for publication on 06.02.2017.

* Work performed at Kantar Health - New York (NY), USA.

Financial support: This study was sponsored by Pfizer Inc.

Conflict of interest: Marco DiBoaventura was an employee of Kantar Health at the time of this study and was a consultant paid by Pfizer for the production of this manuscript; André Vicente Esteves de Carvalhois a Pfizer's speaker; Haline Bianca Squiassi is a Pfizer employee and Cristina Nunes Ferreira was an Pfizer employee at the time of the manuscript was performed.

Health Outcomes Practice, Kantar Health - New York (NY), USA.

Psoriasis Outpatient Clinic, Complexo Hospitalar Santa Casa de Porto Alegre - Porto Alegre (RS), Brazil.

Medical Residency Program, Complexo Hospitalar Santa Casa de Porto Alegre - Porto Alegre (RS), Brazil.

Department of Internal Medicine, Faculdade de Medicina de Ribeirão Preto - Universidade de São Paulo (FMRP-USP) - Ribeirão Preto (SP), Brazil.

Pharmacoeconomics at Pfizer, Inc - São Paulo (SP), Brazil.
}

MAILING ADDRESS:

Haline Bianca Squiassi

E-mail: haline.squiassi@pfizer.com 
icant effect on HRQoL and other outcomes. Patients with psoriasis experience physical discomfort, impaired emotional functioning, negative body image, and daily activity impairments. ${ }^{9}$ Studies of patients in the United States (US) have found that increased severity was associated with decrements in HRQoL, more healthcare provider visits, and frustration with treatment. ${ }^{10,11}$ Even when psoriasis severity is mild, patients report the disease as a significant problem in their daily lives. ${ }^{12}$

The chronic and recurrent nature of the disease requires life-long treatment, which leads to significant economic burden on patients and the healthcare system. Significant increases in healthcare resource utilization and costs have been observed and work productivity also suffers. ${ }^{13}$ A study conducted in the UK found that $59 \%$ of patients with psoriasis reported a high degree of absenteeism (almost one month of work lost per year) ${ }^{14}$ Between 34\%-92\% of patients with psoriasis who were unemployed in the US and the UK reported that their inability to work was due to their condition. ${ }^{14,15}$

However, few studies have examined psoriasis in South America. There is little consensus on whether the prevalence there is lower or comparable relative to other regions indicating that more work is required in this region. . $, 6-8,16,17$ Research is also needed for better documenting the humanistic and economic burden associated with psoriasis in this part of the world, as its effect on the patient may exhibit a similar geographic variation as its very prevalence.

The current study focuses on Brazil. Explorations of psoriasis in Brazil are often limited to convenience samples of patients arriving at public clinics for treatment. ${ }^{18-20}$ Nevertheless, this emerging research suggests patients in Brazil are often overweight or obese, report diminished HRQoL, report increased daily activity impairment, seek multiple healthcare providers' treatment, and report being dissatisfied with treatment course. ${ }^{18-20}$ When psoriasis patients do continue with a prescribed course of treatment, HRQoL improves as long as clinical improvements are also shown. ${ }^{21}$ One study of outpatients in Brazil with psoriasis found that decrements in HRQoL were due to physical symptoms and negative feelings causing heightened distress. ${ }^{22}$ Another study with patients in Brazil distinguished psoriasis from other skin diseases (e.g. vitiligo) by showing that psoriasis more often elicited coping strategies such as control of emotions and stress avoidance. ${ }^{23}$

Although the literature is generally rich in research suggesting a significant burden of psoriasis, more work is needed. Given the observed geographic variability with respect to prevalence, it is possible the effect of psoriasis on the patient may also vary by region. The aim of this study was to extend the current body of research conducted in Brazil by using the Brazil National Health and Wellness Survey, a general health survey of adults in Brazil, to assess the association between psoriasis, psoriasis severity, and an array of health outcomes, both humanistic and economic.

\section{METHODS}

Data source and procedures

Data from the Brazil 2012 National Health and Wellness Survey (NHWS) were used in the analyses. NHWS is a self-administered, cross-sectional health survey of adults aged 18 years and older in Brazil. Data were collected using a dual methodolo- gy of Internet and computer-assisted Web interviewing (CAWI). This dual approach was used to minimize bias related to Internet access, particularly among the elderly. Invitations to participate in the Brazil NHWS were sent to members of the Lightspeed Research Internet panel via e-mail, and the survey was administered online. Additionally, some respondents (especially those aged 65+ years) were recruited to complete the survey at a centralized facility or in the respondents home. In these cases, trained interviewers assisted the participants with inputting their answers into a computer which had the same interface as those who completed the survey online. A stratified, random sampling procedure (for all participants) was implemented according to gender and age strata (based on the International Database of the U.S. Census [http://www.census.gov/ population/ international/data/idb/informationGateway.php]) for the final sample to be representative of the general Brazilian population. For example, if $14 \%$ of the adult Brazilian population was male, between the ages of 18-29, then the recruitment of NHWS respondents was conducted in such a way as to match this percentage. A total of 12,000 respondents completed the Brazil NHWS.

\section{Sample}

All respondents were included in the analyses and categorized as those reporting a diagnosis of psoriasis vs. those not reporting a diagnosis of psoriasis. The specific type of psoriasis was not asked of respondents. Those who reported a diagnosis of psoriasis were further categorized into mild vs. moderate vs. severe psoriasis based on self-report.

\section{Measures}

Sociodemographics. Age, gender, education level (coded as university graduate, some university, or less than university), annual household income (coded as R\$ $\leq 2000, \mathrm{R} \$ 2001$ to $\mathrm{R} \$ 4000, \mathrm{R} \$$ 4001 to $R \$ 10,000, R \$ \geq 10,001$, or decline to answer), employment (coded as employed or not employed), and private insurance status (coded as yes or no) were assessed. For a broader audience, income was presented henceforth in US currency based on the November 30, 2012 exchange rate of $\$ 0.4745$ USD $=\mathrm{R} \$ 1$ (exchange rate published from the Central Bank of Brazil in November 2012). ${ }^{24}$ That is, categories included USD $\leq \$ 949, \$ 950$ to $\$ 1,898, \$ 1,899$ to $\$ 4,745$, $\geq \$ 4,746$, or decline to answer.

Health history. Each respondent provided height and weight in order to calculate body mass index (BMI) and then were categorized according to Centers for Disease Control and Prevention criteria (coded as underweight, normal, overweight, or obese). Respondents who chose not to provide this information had their BMI set to missing. The Charlson comorbidity index (CCI) was used to provide a summary index of overall comorbidity burden. ${ }^{25}$ Greater total index scores indicate a greater comorbid burden on the patient. Additionally, health-related behaviors of alcohol use (coded as drink or do not drink), smoking (coded as current, former, or never), and exercise behavior (coded as regularly exercise or do not exercise) were assessed.

Psoriasis status and severity. Respondents reported whether they have been or have not been diagnosed with psoriasis by a physician. Those who reported a diagnosis provided the severity of their condition as either mild, moderate, or severe based on the 
percentage of body surface area affected. To guide respondents in their assessment of severity, an image of a palm was provided and the survey asked respondents to estimate the number of palms their psoriasis was present on their body (less than 3\% [mild], 3-10\% [moderate], and $10 \%$ or more [severe]).

HRQoL. HRQoL was measured using the Short Form-12 (version 2) [SF-12v2], a 12-item instrument with strong evidence for reliability and validity. ${ }^{26}$ The items from the SF-12v2 are used to create eight domains (bodily pain, general health, mental health, physical functioning, physical role limitations, emotional role limitations, social functioning, and vitality) along with two summary scores (the mental and physical component summary scores). The mental and physical component summary (MCS and PCS, respectively) scores are set to have a population mean of 50 with a standard deviation of 10, with higher scores indicating better HRQoL. A health utility score was also derived (using the SF-6D algorithm) as an overall assessment of a respondent's mental and physical health state that varies from 0 to 1 . Higher scores indicate better health. ${ }^{27}$

Work and activity impairment. Work productivity was measured using the Work Productivity and Activity Impairment (WPAI) questionnaire, a 6-item validated instrument which consists of four metrics: absenteeism (the percentage of work time missed because of one's health in the past seven days), presenteeism (the percentage of impairment experienced while at work in the past seven days because of one's health), overall work impairment (an overall productivity loss estimate that is a combination of absenteeism and presenteeism), and activity impairment (the percentage of impairment in daily activities because of one's health in the past seven days). ${ }^{28}$ Only respondents who reported being employed provided data for absenteeism, presenteeism, and overall work impairment. Percentage of time missed due to absenteeism, presenteeism, and overall work impairment was converted into days per year by multiplying each percentage by 234 days ( 52 working weeks per year $\times 5$ working days per week - 26 days of paid annual leave). All respondents provided data for activity impairment, which was assessed by whether a respondent required assistance from another person in daily activities including taking care of children, getting dressed, bathing yourself, doing everyday chores, and lifting objects heavier than a loaf of bread.

Healthcare resource use. The number of physician visits, emergency room (ER) visits, and hospitalizations in the past six months were also reported by each respondent. These were not specific to psoriasis.

\section{Statistical analyses}

Demographic and patient characteristic differences between those with psoriasis and those without psoriasis as well as among those with varying levels of psoriasis severity (mild vs. moderate vs. severe) were examined using chi-square tests and one-way ANOVA for categorical and continuous variables respectively. Regression models were then conducted to predict outcomes from psoriasis status (yes vs. no) and psoriasis severity (mild vs. moderate vs. severe) controlling for demographics and patient characteristics. For HRQoL variables, general linear models were used due to observed normality in the dependent variables. For work productivity and healthcare resource use variables (which were non-normal), gen- eralized linear models were used specifying a negative binomial distribution and log-link function. All regression models comparing those with and without psoriasis controlled for age, sex, education, annual household income, insurance, BMI, smoking status, and the CCI. All regression models comparing different levels of severity controlled for age, sex, annual household income, and BMI. Statistical significance was set a priori at $\mathrm{p}<.05$.

\section{RESULTS}

A total of 210 respondents (1.75\%) reported a diagnosis of psoriasis. Demographic and health characteristic differences between those diagnosed and those not are presented in table 1. Compared with controls (i.e., those without a diagnosis of psoriasis), those who reported a diagnosis were more likely to report having a university level degree, having a higher annual household income, being employed, having private insurance, being overweight or obese, and a history of smoking.

The overall comorbidity burden (as assessed by the CCI) was significantly greater among those with psoriasis. The top individual comorbid condition was general pain (of any source) in the last month $(36.19 \%$ among those with psoriasis compared with $19.99 \%$ among controls). Anxiety (32.38\%) and insomnia/sleep difficulties $(30.00 \%)$ were also common among those with psoriasis and both of which occurred at rates significantly higher than those without psoriasis (19.99\% and $18.32 \%$, respectively, all $\mathrm{p}<.05)$.

The unadjusted health outcomes for patients with psoriasis compared with controls are reported in table 2. MCS scores and health utilities were significantly lower among respondents with psoriasis; however, PCS scores were no different. Additionally, those with psoriasis reported significantly higher rates of presenteeism, overall work and activity impairment, and healthcare provider visits in the past 6 months.

Among those with psoriasis, most patients reported their condition as mild ( $\mathrm{n}=157 ; 74.76 \%)$. A total of 42 patients $(20.00 \%)$ and 11 patients $(5.24 \%)$ reported their condition as moderate and severe, respectively. Characteristics of those reporting various levels of disease severity are shown in table 3 . Few differences were observed. As psoriasis severity increased, rates of obesity concomitantly increased (from $25.48 \%$ to $38.10 \%$ to $54.55 \%$ for mild, moderate, and severe patients, respectively).

The unadjusted health outcomes for patients with mild, moderate, and severe psoriasis are reported in table 4. PCS scores were significantly lower among the severe group relative to the mild and moderate groups. Absenteeism, presenteeism, overall work impairment, and activity impairment did not differ across different levels of severity groups. However, the mean levels of these outcomes suggest a significant burden, nonetheless. Based on the levels of overall work impairment, between $28 \%$ and $40 \%$ of work time was either missed or rendered ineffective because of health for patients with psoriasis. This corresponded to between 66 and 94 days per employee per year that was either missed or rendered ineffective due to health.

Summaries of regression models used to predict health outcomes from psoriasis diagnosis (yes vs. no) and psoriasis severity (mild vs. moderate vs. severe) are presented (Tables 5 and 6). Table 
5 confirms the increased burden of psoriasis compared with controls as reported in the unadjusted results. MCS and health utilities were significantly lower for those with psoriasis relative to controls
(43.97 vs. 46.89 and 0.67 vs. 0.71 , respectively) and the differences between the groups exceeds established cutoffs for clinical significance ( 3 and 0.03 points for MCS and health utilities, respectively).

\begin{tabular}{|c|c|c|c|c|}
\hline & \multicolumn{4}{|c|}{ Psoriasis diagnosis } \\
\hline & Total $(\mathrm{N}=12000)$ & Control $(\mathrm{N}=11790)$ & Psoriasis $(\mathrm{N}=\mathbf{2 1 0})$ & p value \\
\hline Age (years) & & & & 0.62 \\
\hline Mean \pm SD & $40.28 \pm 15.59$ & $40.27 \pm 15.64$ & $40.80 \pm 12.65$ & \\
\hline Gender & & & & 0.92 \\
\hline Female $(\%)$ & $6017(50.1 \%)$ & $5911(50.1 \%)$ & $106(50.5 \%)$ & \\
\hline Education level & & & & $<.001$ \\
\hline Less than a university education (\%) & $5342(44.5 \%)$ & $5297(44.9 \%)$ & $45(21.4 \%)$ & \\
\hline Some university education (\%) & $2687(22.4 \%)$ & $2637(22.4 \%)$ & $50(23.8 \%)$ & \\
\hline University graduate $(\%)$ & $3971(33.1 \%)$ & $3856(32.7 \%)$ & $115(54.8 \%)$ & \\
\hline Annual household income (in USD) & & & & $<.001$ \\
\hline$\$ 949$ or less $(\%)$ & $3312(27.6 \%)$ & $3279(27.8 \%)$ & $33(15.7 \%)$ & \\
\hline$\$ 950-1,898(\%)$ & $2235(18.6 \%)$ & $2198(18.6 \%)$ & $37(17.6 \%)$ & \\
\hline$\$ 1,899-4,745(\%)$ & $2504(20.9 \%)$ & $2448(20.8 \%)$ & $56(26.7 \%)$ & \\
\hline$\$ 4,746$ or more $(\%)$ & $2496(20.8 \%)$ & $2433(20.6 \%)$ & $63(30.0 \%)$ & \\
\hline Decline to answer (\%) & $1453(12.1 \%)$ & $1432(12.1 \%)$ & $21(10.0 \%)$ & \\
\hline Employment status & & & & 0.013 \\
\hline Employed (\%) & $7654(63.8 \%)$ & $7503(63.6 \%)$ & $151(71.9 \%)$ & \\
\hline Private insurance & & & & $<.001$ \\
\hline Yes $(\%)$ & $5448(45.4 \%)$ & $5316(45.1 \%)$ & $132(62.9 \%)$ & \\
\hline Body mass index category & & & & $<.001$ \\
\hline Underweight (\%) & $402(3.4 \%)$ & $396(3.4 \%)$ & $6(2.9 \%)$ & \\
\hline Normal weight (\%) & $5261(43.8 \%)$ & $5175(43.9 \%)$ & $86(41.0 \%)$ & \\
\hline Overweight (\%) & $3994(33.3 \%)$ & $3940(33.4 \%)$ & $54(25.7 \%)$ & \\
\hline Obese $(\%)$ & $2171(18.1 \%)$ & $2109(17.9 \%)$ & $62(29.5 \%)$ & \\
\hline Decline to provide weight (\%) & $172(1.4 \%)$ & $170(1.4 \%)$ & $2(1.0 \%)$ & \\
\hline Alcohol use & & & & 0.08 \\
\hline Do not drink (\%) & $5288(44.1 \%)$ & $5208(44.2 \%)$ & $80(38.1 \%)$ & \\
\hline Drink alcohol (\%) & $6712(55.9 \%)$ & $6582(55.8 \%)$ & $130(61.9 \%)$ & \\
\hline Smoking behavior & & & & 0.046 \\
\hline Never smoked (\%) & $7118(59.3 \%)$ & $7010(59.5 \%)$ & $108(51.4 \%)$ & \\
\hline Former smoker (\%) & $2794(23.3 \%)$ & $2732(23.2 \%)$ & $62(29.5 \%)$ & \\
\hline Current smoker (\%) & $2088(17.4 \%)$ & $2048(17.4 \%)$ & $40(19.0 \%)$ & \\
\hline Exercise behavior & & & & 0.16 \\
\hline Do not exercise (\%) & $4747(39.6 \%)$ & $4654(39.5 \%)$ & $93(44.3 \%)$ & \\
\hline Regularly exercise (\%) & $7253(60.4 \%)$ & $7136(60.5 \%)$ & $117(55.7 \%)$ & \\
\hline Charlson comorbidity index & & & & $<.001$ \\
\hline Mean \pm SD & $0.30 \pm 0.86$ & $0.29 \pm 0.81$ & $0.64 \pm 2.26$ & \\
\hline
\end{tabular}

\begin{tabular}{|c|c|c|c|c|}
\hline & \multicolumn{4}{|c|}{ Psoriasis diagnosis } \\
\hline & Total $(\mathrm{N}=12000)$ & Control $(\mathrm{N}=11790)$ & Psoriasis $(\mathrm{N}=210)$ & p value \\
\hline SF-12v2: Mental component summary & $46.84 \pm 11.22$ & $46.91 \pm 11.21$ & $42.92 \pm 10.97$ & $<.001$ \\
\hline SF-12v2: Physical component summary & $51.98 \pm 7.75$ & $51.99 \pm 7.75$ & $51.41 \pm 7.52$ & 0.28 \\
\hline Health state utility score & $0.710 \pm 0.137$ & $0.711 \pm 0.138$ & $0.654 \pm 0.107$ & $<.001$ \\
\hline Absenteeism \% & $6.71 \pm 17.67$ & $6.68 \pm 17.64$ & $8.24 \pm 19.27$ & 0.29 \\
\hline Presenteeism \% & $17.82 \pm 26.04$ & $17.68 \pm 26.00$ & $25.03 \pm 27.01$ & $<.001$ \\
\hline Overall work impairment $\%$ & $21.63 \pm 29.51$ & $21.49 \pm 29.49$ & $28.80 \pm 29.82$ & 0.003 \\
\hline Activity impairment $\%$ & $21.89 \pm 28.38$ & $21.77 \pm 28.35$ & $28.95 \pm 29.23$ & $<.001$ \\
\hline Healthcare provider visits in past 6 months & $4.70 \pm 6.85$ & $4.66 \pm 6.84$ & $6.69 \pm 7.31$ & $<.001$ \\
\hline Emergency room visits in the past 6 months & $0.57 \pm 1.82$ & $0.57 \pm 1.82$ & $0.79 \pm 1.89$ & 0.08 \\
\hline Hospitalizations in the past 6 months & $0.22 \pm 1.14$ & $0.22 \pm 1.15$ & $0.25 \pm 0.83$ & 0.77 \\
\hline
\end{tabular}


Upon covariate adjustment, PCS scores were significantly lower for those with severe psoriasis compared with those with mild psoriasis (45.078 vs. $51.783, \mathrm{p}<.05$; table 6). No differences were observed with respect to MCS or health utilities or other outcomes.

Additionally, presenteeism $(22.08 \%$ vs. $16.95 \%$, which equates to an additional 10 days per employee per year missed

\begin{tabular}{|c|c|c|c|c|c|}
\hline & \multicolumn{5}{|c|}{ Psoriasis severity } \\
\hline & Total $(\mathrm{N}=210)$ & Mild (N=157) & Moderate $(\mathrm{N}=42)$ & Severe $(\mathrm{N}=11)$ & p value \\
\hline Age (years) & & & & & 0.74 \\
\hline Mean \pm SD & $40.80 \pm 12.65$ & $41.06 \pm 12.75$ & $40.55 \pm 12.26$ & $38.00 \pm 13.55$ & \\
\hline Gender & & & & & 0.09 \\
\hline Female $(\%)$ & $106(50.5 \%)$ & $75(47.8 \%)$ & $22(52.4 \%)$ & $9(81.8 \%)$ & \\
\hline Education level & & & & & 0.65 \\
\hline Less than a university education (\%) & $45(21.4 \%)$ & $32(20.4 \%)$ & $10(23.8 \%)$ & $3(27.3 \%)$ & \\
\hline Some university education (\%) & $50(23.8 \%)$ & $35(22.3 \%)$ & $13(31.0 \%)$ & $2(18.2 \%)$ & \\
\hline University graduate $(\%)$ & $115(54.8 \%)$ & $90(57.3 \%)$ & $19(45.2 \%)$ & $6(54.5 \%)$ & \\
\hline Annual household income (in USD) & & & & & 0.006 \\
\hline$\$ 949$ or less (\%) & $33(15.7 \%)$ & $22(14.0 \%)$ & $10(23.8 \%)$ & $1(9.1 \%)$ & \\
\hline$\$ 950-1,898(\%)$ & $37(17.6 \%)$ & $28(17.8 \%)$ & $8(19.0 \%)$ & $1(9.1 \%)$ & \\
\hline$\$ 1,899-4,745(\%)$ & $56(26.7 \%)$ & $45(28.7 \%)$ & $10(23.8 \%)$ & $1(9.1 \%)$ & \\
\hline$\$ 4,746$ or more $(\%)$ & $63(30.0 \%)$ & $51(32.5 \%)$ & $9(21.4 \%)$ & $3(27.3 \%)$ & \\
\hline Decline to answer (\%) & $21(10.0 \%)$ & $11(7.0 \%)$ & $5(11.9 \%)$ & $5(45.5 \%)$ & \\
\hline Employment status & & & & & 0.18 \\
\hline Employed (\%) & $151(71.9 \%)$ & $111(70.7 \%)$ & $34(81.0 \%)$ & $6(54.5 \%)$ & \\
\hline Private insurance & & & & & 0.48 \\
\hline Yes $(\%)$ & $132(62.9 \%)$ & $102(65.0 \%)$ & $23(54.8 \%)$ & $7(63.6 \%)$ & \\
\hline Body mass index category & & & & & 0.008 \\
\hline Underweight (\%) & $6(2.9 \%)$ & $3(1.9 \%)$ & $3(7.1 \%)$ & $0(0.0 \%)$ & \\
\hline Normal weight (\%) & $86(41.0 \%)$ & $69(43.9 \%)$ & $13(31.0 \%)$ & $4(36.4 \%)$ & \\
\hline Overweight (\%) & $54(25.7 \%)$ & $44(28.0 \%)$ & $10(23.8 \%)$ & $0(0.0 \%)$ & \\
\hline Obese (\%) & $62(29.5 \%)$ & $40(25.5 \%)$ & $16(38.1 \%)$ & $6(54.5 \%)$ & \\
\hline Decline to provide weight (\%) & $2(1.0 \%)$ & $1(0.6 \%)$ & $0(0.0 \%)$ & $1(9.1 \%)$ & \\
\hline Alcohol use & & & & & 0.80 \\
\hline Do not drink (\%) & $80(38.1 \%)$ & $58(36.9 \%)$ & $17(40.5 \%)$ & $5(45.5 \%)$ & \\
\hline Drink alcohol (\%) & $130(61.9 \%)$ & $99(63.1 \%)$ & $25(59.5 \%)$ & $6(54.5 \%)$ & \\
\hline Smoking behavior & & & & & 0.42 \\
\hline Never smoker (\%) & $108(51.4 \%)$ & $77(49.0 \%)$ & $23(54.8 \%)$ & $8(72.7 \%)$ & \\
\hline Former smoker (\%) & $62(29.5 \%)$ & $51(32.5 \%)$ & $10(23.8 \%)$ & $1(9.1 \%)$ & \\
\hline Current smoker (\%) & $40(19.0 \%)$ & $29(18.5 \%)$ & $9(21.4 \%)$ & $2(18.2 \%)$ & \\
\hline Exercise behavior & & & & & 0.41 \\
\hline Do not exercise (\%) & $93(44.3 \%)$ & $68(43.3 \%)$ & $18(42.9 \%)$ & $7(63.6 \%)$ & \\
\hline Regularly exercise (\%) & $117(55.7 \%)$ & $89(56.7 \%)$ & $24(57.1 \%)$ & $4(36.4 \%)$ & \\
\hline Charlson comorbidity index & & & & & 0.75 \\
\hline Mean \pm SD & $0.64 \pm 2.26$ & $0.69 \pm 2.57$ & $0.57 \pm 0.86$ & $0.18 \pm 0.40$ & \\
\hline
\end{tabular}

\begin{tabular}{lcccc}
\multicolumn{2}{r}{ TABLE 4: Health outcomes in those diagnosed with mild, moderate, or severe psoriasis (Mean \pm SD) } \\
\cline { 2 - 5 } & \multicolumn{4}{c}{ Psoriasis severity } \\
\cline { 2 - 5 } & Total (N=210) & Mild (N=157) & Moderate (N=42) & Severe (N=11) \\
\hline SF-12v2: MCS & $42.92 \pm 10.97$ & $43.23 \pm 11.22$ & $42.45 \pm 10.54$ & $40.23 \pm 9.26$ \\
SF-12v2: PCS & $51.41 \pm 7.52$ & $51.91 \pm 6.86$ & $51.15 \pm 7.99$ & $45.23 \pm 11.78$ \\
Health state utility score & $0.654 \pm 0.107$ & $0.658 \pm 0.104$ & $0.653 \pm 0.118$ & $0.587 \pm 0.076$ \\
Absenteeism \% & $8.24 \pm 19.27$ & $9.38 \pm 21.66$ & $5.15 \pm 10.01$ & $4.75 \pm 6.60$ \\
Presenteeism \% & $25.03 \pm 27.01$ & $23.68 \pm 26.52$ & $25.88 \pm 27.76$ & $48.00 \pm 26.83$ \\
Overall work impairment \% & $28.80 \pm 29.82$ & $28.53 \pm 30.64$ & $28.32 \pm 28.70$ & $39.75 \pm 17.63$ \\
Activity impairment \% & $28.95 \pm 29.23$ & $27.52 \pm 27.61$ & $32.62 \pm 33.86$ & $35.45 \pm 33.57$ \\
Physician visits in the past 6 months & $6.69 \pm 7.31$ & $6.51 \pm 6.76$ & $7.40 \pm 9.52$ & $6.55 \pm 5.47$ \\
Emergency room visits in the past 6 months & $0.79 \pm 1.89$ & $0.82 \pm 2.05$ & $0.74 \pm 1.25$ & $0.64 \pm 1.50$ \\
Hospitalizations in the past 6 months & $0.25 \pm 0.83$ & $0.20 \pm 0.70$ & $0.43 \pm 1.27$ \\
\hline
\end{tabular}


due to health for those with psoriasis), activity impairment (26.52\% vs. $20.97 \%$ ), and the number of physician visits (5.18 vs. 4.27 ) were all significantly higher among those with diagnosed psoriasis (all $\mathrm{p}<.05)$. No differences were observed across levels of severity.

\section{DISCUSSION}

The current study provides evidence of the burden that psoriasis imposes on the quality of life and economic outcomes in Brazil, a geographic region in need of further examination. Psoriasis

TABLE 5: Summary table of the adjusted effect of psoriasis on health outcomes

\begin{tabular}{|c|c|c|c|c|c|c|c|}
\hline Variable & $\begin{array}{l}\text { Psoriasis } \\
\text { (Adj Mean) }\end{array}$ & $\begin{array}{c}\text { Control } \\
\text { (Adj Mean) }\end{array}$ & B & & 95\% LCL & 95\% UCL & $\mathbf{P}$ \\
\hline Mental component summary & 43.965 & 46.887 & -2.922 & -- & -4.371 & -1.473 & $<.001$ \\
\hline Physical component summary & 51.824 & 51.982 & -0.158 & -- & -1.173 & 0.856 & 0.76 \\
\hline Health utilities & 0.668 & 0.711 & -0.043 & -- & -0.061 & -0.025 & $<.0001$ \\
\hline Variable & $\begin{array}{l}\text { Psoriasis } \\
\text { (Adj Mean) }\end{array}$ & $\begin{array}{c}\text { Control } \\
\text { (Adj Mean) }\end{array}$ & B & Rate Ratio & $95 \% \mathrm{LCL}$ & 95\% UCL & $\mathbf{P}$ \\
\hline Absenteeism \% & 7.868 & 6.279 & 0.226 & 1.253 & -0.235 & 0.686 & 0.34 \\
\hline Presenteeism \% & 22.077 & 16.949 & 0.264 & 1.303 & 0.011 & 0.518 & 0.041 \\
\hline Overall work impairment \% & 25.741 & 20.679 & 0.219 & 1.245 & -0.017 & 0.455 & 0.07 \\
\hline Activity impairment \% & 26.524 & 20.966 & 0.235 & 1.265 & 0.051 & 0.419 & 0.012 \\
\hline Number of physician visits & 5.184 & 4.270 & 0.194 & 1.214 & 0.007 & 0.381 & 0.042 \\
\hline Number of emergency room visits & 0.626 & 0.491 & 0.243 & 1.275 & -0.204 & 0.689 & 0.29 \\
\hline Number of hospitalizations & 0.192 & 0.198 & -0.027 & 0.973 & -0.659 & 0.605 & 0.93 \\
\hline
\end{tabular}

\section{TABLE 6: Summary table of the adjusted effect of psoriasis severity on health outcomes}

\begin{tabular}{|c|c|c|c|c|c|c|}
\hline Variable & Adjusted mean comparison & b & & $95 \%$ LCL & $95 \%$ UCL & $\mathbf{P}$ \\
\hline \multicolumn{7}{|c|}{ Mental component summary } \\
\hline Moderate vs. mild & 42.795 vs. 42.960 & -0.165 & -- & -3.862 & 3.532 & 0.93 \\
\hline Severe vs. mild & 42.748 vs. 42.960 & -0.212 & -- & -7.237 & 6.813 & 0.95 \\
\hline \multicolumn{7}{|c|}{ Physical component summary } \\
\hline Moderate vs. mild & 51.676 vs. 51.783 & -0.106 & -- & -2.629 & 2.416 & 0.93 \\
\hline Severe vs. mild & 45.078 vs. 51.783 & -6.704 & -- & -11.497 & -1.911 & 0.006 \\
\hline \multicolumn{7}{|l|}{ Health utilities } \\
\hline Moderate vs. mild & 0.659 vs. 0.656 & 0.003 & -- & -0.033 & 0.040 & 0.86 \\
\hline Severe vs. mild & 0.594 vs. 0.656 & -0.063 & -- & -0.132 & 0.007 & 0.07 \\
\hline Variable & Adjusted mean comparison & $\mathbf{b}$ & Rate Ratio & $95 \%$ LCL & 95\% UCL & $\mathbf{P}$ \\
\hline \multicolumn{7}{|l|}{ Absenteeism \% } \\
\hline Moderate vs. mild & 5.523 vs. 6.711 & -0.195 & 0.823 & -1.180 & 0.790 & 0.70 \\
\hline Severe vs. mild & 6.648 vs. 6.711 & -0.010 & 0.991 & -2.463 & 2.444 & 0.99 \\
\hline \multicolumn{7}{|l|}{ Presenteeism \% } \\
\hline Moderate vs. mild & 23.350 vs. 21.407 & 0.087 & 1.091 & -0.385 & 0.559 & 0.72 \\
\hline Severe vs. mild & 45.515 vs. 21.407 & 0.754 & 2.126 & -0.354 & 1.863 & 0.18 \\
\hline \multicolumn{7}{|c|}{ Overall work impairment \% } \\
\hline Moderate vs. mild & 26.870 vs. 25.460 & 0.054 & 1.055 & -0.384 & 0.491 & 0.81 \\
\hline Severe vs. mild & 32.593 vs. 25.460 & 0.247 & 1.280 & -0.912 & 1.406 & 0.68 \\
\hline \multicolumn{7}{|c|}{ Activity impairment \% } \\
\hline Moderate vs. mild & 30.351 vs. 26.205 & 0.147 & 1.158 & -0.221 & 0.515 & 0.43 \\
\hline Severe vs. mild & 38.175 vs. 26.205 & 0.376 & 1.457 & -0.329 & 1.081 & 0.30 \\
\hline \multicolumn{7}{|c|}{ Number of physician visits } \\
\hline Moderate vs. mild & 6.870 vs. 6.229 & 0.177 & -0.249 & 0.445 & 0.31 & 0.18 \\
\hline Severe vs. mild & 5.695 vs. 6.229 & 0.327 & -0.730 & 0.551 & 0.08 & 0.33 \\
\hline \multicolumn{7}{|c|}{ Number of emergency room visits } \\
\hline Moderate vs. mild & 0.441 vs. 0.544 & -0.209 & 0.811 & -0.870 & 0.452 & 0.54 \\
\hline Severe vs. mild & 0.380 vs. 0.544 & -0.358 & 0.699 & -1.683 & 0.967 & 0.60 \\
\hline \multicolumn{7}{|c|}{ Number of hospitalizations } \\
\hline Moderate vs. mild & 0.129 vs. 0.064 & 0.529 & -0.343 & 1.732 & 1.72 & 0.19 \\
\hline Severe vs. mild & 0.084 vs. 0.064 & 1.067 & -1.827 & 2.355 & 0.06 & 0.80 \\
\hline
\end{tabular}


adversely affected several health outcomes and, in some cases, these outcomes further varied by reported severity of the condition. Overall, patient characteristics were comparable to other studies in terms of comorbidities and unhealthy lifestyle risk factors (e.g. smoking and obesity). ${ }^{8,29}$ A trend showing women may experience more severe symptoms than men coincides with other studies., ${ }^{40,12}$ However, the pattern of higher levels of education, higher income, and higher rates of private insurance among those with psoriasis (which is different than past studies conducted elsewhere) suggests that diagnosis may be a function of greater healthcare access in Brazil. In other words, it is possible that among patients with psoriasis, those with greater education, higher income, and private insurance, are more likely to get diagnosed with psoriasis because they have better access to diagnosing physicians and seek medical attention more regularly. This would further suggest that there may be a sizable undiagnosed population in Brazil (more so than in other countries), particularly among those with less healthcare access (i.e., those with only the Unified Health System as opposed to private insurance coverage) though additional epidemiological research would be necessary to test this hypothesis.

With respect to HRQoL, the greatest differences between patients with psoriasis and those without was on MCS and health utilities, both of which exceeded clinically relevant cutoffs. The values from our study were comparable to psoriasis studies conducted in the US that used either the SF-12v2 or SF-36v2. ${ }^{30-32}$ The effects for MCS and health utilities did not significantly vary by severity, though there was a trend for worse outcomes among those who were severe relative to those who were mild. PCS was not significantly different between patients with psoriasis and controls, though differences across severity were observed as also reported in past literature. ${ }^{30}$ This pattern of results suggests that the presence itself of psoriasis may result in a significant mental health burden (due to the stigma of the condition, social anxiety, etc), but greater severity does not appreciably influence the size of this burden. Conversely, with most patients in our sample being of mild severity, the physical burden is not particularly debilitating unless the condition is severe. This lack of physical burden may also be a function of the greater healthcare access of patients with psoriasis. Although our analyses controlled for socioeconomic-related variables, it is possible that the health care these patients receive (for all their conditions) may be better than control participants; this could mask some of the underlying physical burden of psoriasis itself.

Results for the work productivity indices varied in its similarity to past work. Although rates of impairment were comparable to other studies, these rates did not differ from controls. ${ }^{14,18-19}$, ${ }^{33-37}$ In part, this may be a sample size limitation (only 150 patients with psoriasis were currently employed); rates of impairment were generally a third higher among those with psoriasis compared with those without. Nevertheless, activity impairment was significantly higher among those with psoriasis. None of these variables varied significantly by severity; however, the trends suggest a potential effect for some of these variables. For example, patients with severe psoriasis experience a particularly high rate of presenteeism (45.5\%) compared to the mild psoriasis group (21.4\%).

Although the number of hospitalizations and emergency room visits were statistically identical for those with psoriasis and those without psoriasis, approximately $25 \%$ more physician visits were reported among those with psoriasis. The number of visits did not vary by severity.

As study limitation, all data from the NHWS were patient-reported, so no clinical verification of diagnosis, comorbidities, or healthcare resource use was available. Additionally, because the NHWS is a cross-sectional study, a causal relationship between psoriasis and outcomes measured can only be speculated from the available data. Although the NHWS provides a broad demographic representation of the Brazilian adult population, our sample of patients with psoriasis may not generalize to the population of patients with psoriasis. Indeed, our distribution of severity skewed towards the milder category suggesting our estimates of disease burden may be underestimates. Furthermore, compared with the general Brazil population, NHWS has a smaller proportion of respondents from lower-socioeconomic strata, reflecting people with the motivation, ability, and access to participate in an online survey. Therefore, NHWS respondents tend to be wealthier and better educated, such that the current study results may not generalize to the broader Brazil population or the low income population in particular.

\section{CONCLUSION}

In sum, these results suggest a significant burden of patients with psoriasis across both humanistic and economic outcomes. The association between psoriasis and mental health aspects and health utilities were particularly strong and exceeded what would be considered clinically meaningful. Although cost analyses were not performed in this study, these results suggest a significant economic burden from a societal perspective. It is also worth noting that this burden may be underestimated as respondents with better socioeconomic status and healthcare access were more likely to be diagnosed; it is likely a number of patients from the control group have psoriasis but have not been diagnosed.

Understanding the full extent of the burden of psoriasis in Brazil will aid in facilitating public awareness, doctor-patient relationships, and beneficial healthcare policies. Despite universal healthcare in Brazil (Unified Health System; i.e., SUS), past studies have outlined the challenges psoriasis patients experience in receiving adequate care in Brazil. ${ }^{18}$ Using humanistic and economic indicators of the burden of psoriasis, this study researched a national sample representative of the adult population in Brazil, a critical extension of past work that has typically relied on small convenience samples. $]$ 


\section{REFERENCES}

1. Christophers E. Psoriasis - epidemiology and clinical spectrum. Clin Exp Dermatol. 2001;26:314-20

2. Parisi R, Symmons DP, Griffiths CE, Ashcroft DM; Identification and Management of Psoriasis and Associated ComorbidiTy (IMPACT) project team. Global epidemiology of psoriasis: a systematic review of incidence and prevalence. $J$ Invest Dermatol. 2013;133:377-85.

3. Gelfand JM, Stern RS, Nijsten T, Feldman SR, Thomas J, Kist J, et al. The prevalence of psoriasis in African Americans: results from a population-based study. J Am Acad Dermatol. 2005;52:23-6.

4. Gelfand JM, Weinstein R, Porter SB, Neimann AL, Berlin JA, Margolis DJ. Prevalence and treatment of psoriasis in the United Kingdom: a population-based study. Arch Dermatol. 2005;141:1537-41.

5. Augustin M, Reich K, Glaeske G, Schaefer I, Radtke M. Co-morbidity and agerelated prevalence of psoriasis: analysis of health insurance data in Germany. Acta Derm Venereol. 2010;90:147-51.

6. Sociedade Brasileira de Dermatologia. Consenso Brasileiro de Psoríase 2012 Guias de avaliação e tratamento. 2. ed. Rio de Janeiro: Sociedade Brasileiro de Dermatologia; 2012.

7. Brasil. Ministério da Saúde. Portaria n0 1229, de 5 de novembro de 2013. Aprova 0 Protocolo Clínico e Diretrizes Terapêutica - Psoríase. [cited 2013 Nov 16]. Available from: portal.saude.gov.br/portal/arquivos/pdf/cp 09 psoriase 2012.pdf.

8. Chandran V, Raychaudhuri SP. Geoepidemiology and environmental factors of psoriasis and psoriatic arthritis. J Autoimmun. 2010;34:J314-21.

9. de Korte J, Sprangers MA, Mombers FM, Bos JD. Quality of life in patients with psoriasis: a systematic literature review. J Investig Dermatol Symp Proc. 2004;9:140-7.

10. Gelfand JM, Feldman SR, Stern RS, Thomas J, Rolstad T, Margolis DJ. Determinants of quality of life in patients with psoriasis: a study from the US population. J Am Acad Dermatol. 2004;51:704-8.

11. DiBonaventura Md, Wagner S, Waters $\mathrm{H}$, Carter C. Treatment patterns and perceptions of treatment attributes, satisfaction and effectiveness among patients with psoriasis. J Drugs Dermatol. 2010:9:938-44

12. Stern RS, Nijsten T, Feldman SR, Margolis DJ, Rolstad T. Psoriasis is common, carries a substantial burden even when not extensive, and is associated with widespread treatment dissatisfaction. J Investig Dermatol Symp Proc. 2004:9:136-9.

13. Raho G, Koleva DM, Garattini L, Naldi L. The burden of moderate to severe psoriasis: an overview. Pharmacoeconomics. 2012;30:1005-13.

14. Finlay AY, Coles EC. The effect of severe psoriasis on the quality of life of 369 patients. Br J Dermatol. 1995;132:236-44.

15. Armstrong AW, Schupp C, Wu J, Bebo B. Quality of Life and Work Productivity Impairment among Psoriasis Patients: Findings from the National Psoriasis Foundation Survey Data 2003-2011. PLoS One. 2012;7:e52935.

16. Toloza SM, Valle-Oñate R, Espinoza LR. Psoriatic arthritis in South and Central America. Curr Rheumatol Rep. 2011:13:360-8.

17. Toloza SM, Vega-Hinojosa O, Chandran V, Valle Onate R, Espinoza LR. Psoriasis and psoriatic arthritis in Peruvian aborigines: a report from the GRAPPA 2011 annual meeting. J Rheumatol. 2012;39:2216-9.

18. Sabbag CY. Brazilian survey with patients with psoriasis. Rev Latinoam Psoriasis Artritis Psoriásica. 2011:3:7-14

19. Mingnorance R, Loureiro S, Okino L. Psoriasis patients: quality of life and psychosocial adjustment. An Bras Dermatol. 2002;77:147-59.
20. Taborda ML, Weber MB, Teixeira KA, Lisboa AP, Welter Ede Q. Evaluation of the quality of life and psychological distress of patients with different dermatoses in a dermatology referral center in southern Brazil. An Bras Dermatol. 2010;85:52-6.

21. Torres RA, Silva SA, Magalhães RF, Morcillo AM, Velho PE. Comparison of quality of life questionnaires and their correlation with the clinical course of patients with psoriasis. An Bras Dermatol. 2011;86:45-9.

22. Tejada Cdos S, Mendoza-Sassi RA, Almeida HL Jr, Figueiredo PN, Tejada VF Impact on the quality of life of dermatological patients in southern Brazil. An Bras Dermatol. 2011;86:1113-21.

23. da Silva JDT, Muller MC, Bonamigo RR. Coping strategies and stress levels in patients with psoriasis. An Bras Dermatol. 2006;81:143-9.

24. Brasil. Banco Central do Brasil. Taxas de Câmbios: Conversão de moedas. [cited 2016 January 31]. Available from: http://www4.bcb.gov.br/pec/conversao/ conversao.asp.

25. Charlson ME, Pompei P, Ales KL, MacKenzie CR. A new method of classifying prognostic comorbidity in longitudinal studies: development and validation. $J$ Chronic Dis. 1987;40:373-83.

26. Ware J Jr, Kosinski M, Keller SD. A 12-Item Short-Form Health Survey: construction of scales and preliminary tests of reliability and validity. Med Care. 1996;34:220-33

27. Brazier J, Roberts J, Deverill M. The estimation of a preference-based measure of health from the SF-36. J Health Econ. 2002;21:271-92.

28. Reilly MC, Zbrozek AS, Dukes EM. The validity and reproducibility of a work productivity and activity impairment instrument. Pharmacoeconomics. 1993;4:353-65.

29. Husted JA, Thavaneswaran A, Chandran V, Eder L, Rosen CF, Cook RJ, Gladman DD. Cardiovascular and other comorbidities in patients with psoriatic arthritis: a comparison with patients with psoriasis. Arthritis Care Res (Hoboken). 2011;63:1729-35

30. Grozdev I, Kast D, Cao L, Carlson D, Pujari P, Schmotzer B, et al. Physical and mental impact of psoriasis severity as measured by the compact Short Form-12 Health Survey (SF-12) quality of life tool. J Invest Dermatol. 2012;132:1111-6.

31. Lundberg L, Johannesson M, Silverdahl M, Hermansson C, Lindberg M. Healthrelated quality of life in patients with psoriasis and atopic dermatitis measured with SF-36, DLQI and a subjective measure of disease activity. Acta Derm Venereol. 2000;80:430-4.

32. Lundberg L, Johannesson M, Silverdahl M, Hermansson C, Lindberg M. Quality of life, health-state utilities and willingness to pay in patients with psoriasis and atopic eczema. Br J Dermatol. 1999;141:1067-75

33. Augustin M, Krüger K, Radtke MA, Schwippl I, Reich K. Disease severity, quality of life and health care in plaque-type psoriasis: a multicenter cross-sectional study in Germany. Dermatology. 2008;216:366-72.

34. Schmitt JM, Ford DE.. Work limitations and productivity loss are associated with health-related quality of life but not with clinical severity in patients with psoriasis Dermatology. 2006;213:102-10.

35. Naim A, Carter C, Waters H, Annunziata K, Piech C. Assessing work productivity loss, absenteeism, and presenteeism among psoriasis sufferers in the United States. J Am Acad Dermatol. 2009;60:AB180.

36. de Arruda LH, De Moraes AP. The impact of psoriasis on quality of life. $\mathrm{Br}$ Dermatol. 2001;144:33-6

37. Pearce DJ, Singh S, Balkrishnan R, Kulkarni A, Fleischer AB, Feldman SR. The negative impact of psoriasis on the workplace. J Dermatolog Treat. 2006;17:24-8.

How to cite this article: DiBonaventura M, Carvalho AVE, Souza CS, Squiassi HB, Ferreira CN. The association between psoriasis and healthrelated quality of life, work productivity, and healthcare resource use in Brazil. An Bras Dermatol. 2018;93(2):197-204. 